\title{
COMMUNICATION
}

Cite this: DOI: $10.1039 /$ xoxxooooox

\section{Broadening the Chemical Scope of Laccases: Selective Deprotection of $N$-Benzyl Groups}

\author{
Lía Martínez-Montero, ${ }^{a}$ Alba Díaz-Rodríguez, ${ }^{a, b}$ Vicente Gotor, ${ }^{a}$ Vicente Gotor- \\ Fernández, ${ }^{* a}$ and Iván Lavandera*a
}

Received ooth January 2012,

Accepted ooth January 2012

DOI: $10.1039 / \times 0 x x 00000 x$

www.rsc.org/

Laccase from Trametes versicolor together with TEMPO has been found as a very efficient system to deprotect $N$ benzylated primary amines, differing from previously described methods since it uses oxygen as mild oxidant in aqueous medium. Chemoselective removal of the benzyl group was achieved with excellent yields when secondary amine and alcohol moieties were also present.

The development of efficient deprotection protocols is crucial in organic synthesis. ${ }^{1}$ The presence of multiple functionalities with similar reactivities in the target molecule and harsh conditions often employed in deprotection reactions hampers the implementation of these methodologies. Therefore, there is a need for alternative, more sustainable and chemoselective processes to modify a specific position.

The reactivity of free amines can be a challenge when preparing increasingly complex compounds, thus requiring protection during a chemical transformation. Due to the abundance of amines in organic molecules, ${ }^{2}$ the employment of amino protecting groups is commonplace in many synthetic schemes, such as carbamates, amides and sulfonamides. In particular, the benzyl group is commonly used as protecting group in different synthetic areas. Its simple introduction with benzyl halides and inherent stability under basic conditions provides a myriad of possibilities to perform further transformations. $N$-benzyl groups are typically cleaved using reductive methods, with palladium-catalyzed hydrogenolysis often employed.1,3-7 Also oxidative or photolytic debenzylations can be carried out with a variety of reagents such as cerium ammonium nitrate (CAN), ${ }^{8}$ diisopropyl azodicarboxylate (DIAD), ${ }^{9}$ titanium(III) chloride in combination with iodine, ${ }^{10}$ or alkali metal bromide formed mixing $\mathrm{KBr}$ and Oxone ${ }^{\circledR}, 11$ among others. Finally, Lewis acids such as boron reagents have also been applied to this process. ${ }^{12}$
Unfortunately, these methodologies make use of organic solvents and, in some cases, high temperatures and stoichiometric amounts of poisoning reagents. Therefore, biocatalytic methods can provide clear advantages in the development of synthetic route employing mild reaction conditions in aqueous media. In fact, one of the most appreciated advantages ligated to their use is the ability to achieve selective protection/deprotection steps avoiding multi-step protocols. ${ }^{13}$ Moreover, enzymes have proven their effectiveness in the selective modification of a wide range of functionalities, mainly using hydrolytic or redox enzymes. For instance, acylases, esterases, lipases and proteases are recognized as efficient enzymes for the deprotection of alkyl esters including benzylic ones, ${ }^{14-18}$ amides $^{19}$ and carbamates. ${ }^{20}$ Also, oxidoreductases have shown the potential to carry out $N$-deprotection reactions. Cytochrome P450s have been described as catalysts to perform debenzylations, ${ }^{21}$ and laccases to cleave the $p$-methoxyphenyl (PMP) group. ${ }^{22}$

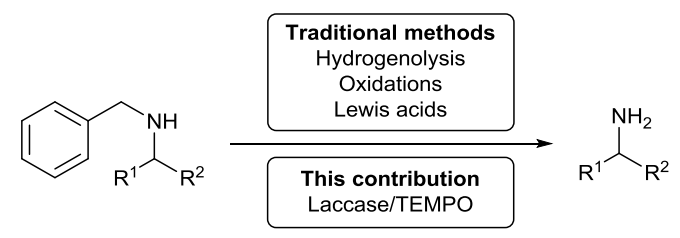

Scheme 1 Laccase-catalyzed debenzylation protocol vs typical chemical methods.

Herein we wish to report our latest results in the development of an efficient $\mathrm{N}$-benzyl deprotection reaction taken advantage of the use of laccases (Scheme 1),23-27 which are multi-copper enzymes found in a myriad of bacteria, fungi and plants. These oxidases reduce $\mathrm{O}_{2}$ into $\mathrm{H}_{2} \mathrm{O}$ at the expense of the oxidation of the corresponding substrate. In the case of some specific substrates such as primary amines or primary and secondary alcohols, it is compulsory the use of a chemical mediator that acts as the true oxidant species, giving access to the so-called laccase mediator systems (LMS). In particular, 2,2,6,6-tetramethylpiperidin-1-yl)oxy 
radical (TEMPO), has been recurrently applied as compatible oxidant, ${ }^{28-32}$ but also other mediators such as 2,2'-azino-bis(3ethylbenzothiazoline-6-sulphonic acid) (ABTS), or 2azaadamantane $N$-oxyl (AZADO) have been successfully used. ${ }^{33}$ Recently, this oxoammonium salt has been employed in combination with laccases ${ }^{34}$ or metal catalyst systems ${ }^{35}$ to achieve mild and selective oxidations of alcohols and amino alcohols.

The application of our laccase/TEMPO system using oxygen as final oxidant to a selected panel of $N$-benzylated primary amines will be disclosed, demonstrating its regio- and chemoselectivity in the presence of protected secondary amines and alcohols, also comparing its eco-efficiency with other traditional chemical deprotecting strategies.

As a continuation of our previous study related to the synthesis of interesting lactones and lactams using the laccase/TEMPO system, ${ }^{30,36}$ 5-(benzylamino)pentan-1-ol (1a) was synthesized and exposed to the previously optimized conditions. After reaction optimization (see ESI), laccase from Trametes versicolor and TEMPO (33\% mol) were employed in Tris. $\mathrm{HCl} 200 \mathrm{mM}$ buffer $\mathrm{pH} 5$ at $30^{\circ} \mathrm{C}$ under orbital stirring, expecting the formation of the corresponding $N$-benzylated lactam 1c. ${ }^{36}$ Surprisingly, a mixture of hemiacetal 1d and lactone $\mathbf{1 e}$ was attained in quantitative conversion (Scheme 2a). This can be explained if the oxidation takes place preferentially at the benzylic position (leaving the primary alcohol intact) affording amino alcohol $\mathbf{1 b}$ after hydrolysis of the imine intermediate. This compound would lead to derivatives $\mathbf{1 d}$ and $\mathbf{1 e}$ after chemoselective reoxidation of the amino group (Scheme 2b). ${ }^{36}$

a)

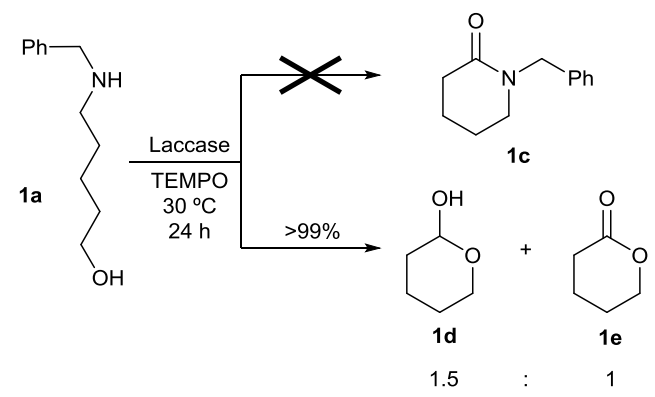

b)

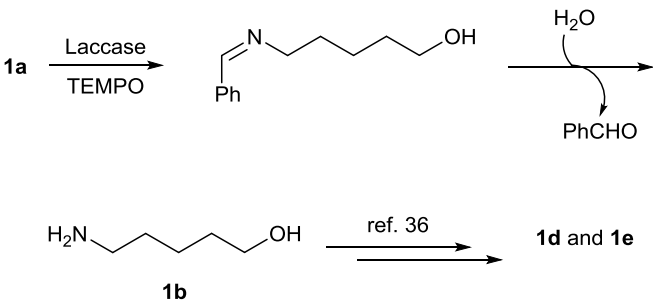

Scheme 2 a) Formation of hemiacetal $\mathbf{1 d}$ and lactone 1e starting from $\mathrm{N}$ benzylated amino alcohol 1a. b) Sequence pathway involving an $N$-debenzylation step.

Despite this result was unexpected, we found promising the first debenzylation step, as this method utilized a substoichiometric amount of the oxidant and proceeded under aerobic conditions in aqueous medium. In fact, this methodology could turn into an orthogonal deprotection strategy. While not suitable for amines over primary positions due to the formation of the corresponding aldehydes, this method could perfectly work over $\mathrm{N}$-benzylated amines at secondary positions. Thus, to study the scope of this reaction, a series of primary amines was benzylated to obtain derivatives 2a-8a (Table 1), and the laccase-mediated deprotection reaction was performed under the previously described conditions. Among the different substrates tested, racemic and enantiomerically pure amines were considered, also including amino alcohols and amino esters.

Table 1 Debenzylation of $N$-protected amino derivatives 2a-8a using the laccase/TEMPO system ${ }^{a}$

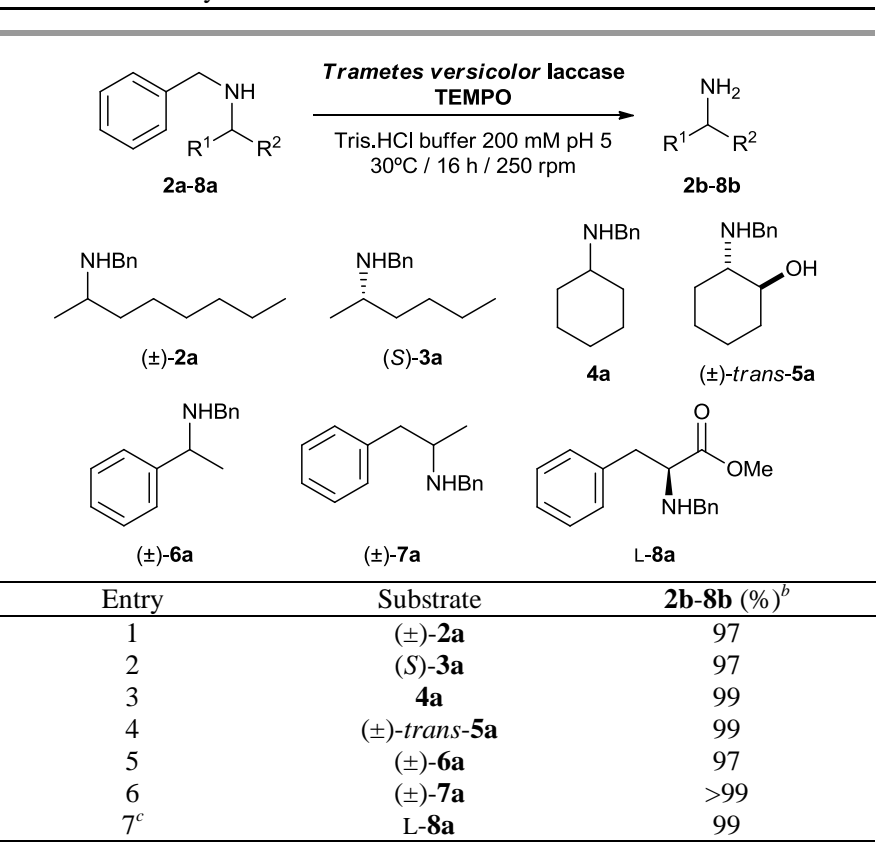

${ }^{a}$ Reaction conditions: 2a-8a $(0.08 \mathrm{mmol})$, T. versicolor laccase $(41 \mathrm{U})$ and TEMPO (33\% mol) in an oxygen-saturated Tris.HCl $200 \mathrm{mM}$ buffer $\mathrm{pH} 5$ at $30^{\circ} \mathrm{C}$ for $16 \mathrm{~h}$ at $250 \mathrm{rpm} .{ }^{b}$ Conversion values measured by GC. ${ }^{c}$ Reaction time: $8 \mathrm{~h}$.

While the blank reactions without laccase and/or TEMPO did not provide any conversion (see ESI), this methodology could be successfully applied over different aliphatic, cyclic and aromatic amines affording deprotected derivatives $\mathbf{2} \mathbf{b}$-8b smoothly and in a very clean fashion, not observing undesired by-products due to, e.g. oxidative transformations (conv $>97 \%$ ). Moreover, when using enantiopure derivatives 3a and 8a (entries 2 and 7), the optical purity of the corresponding amines remained untouched. Also, no loss of diastereoselectivity was observed for substrate ( \pm )-trans-5a (entry 4). Hence, interesting derivatives such as amphetamine $\mathbf{7 a}$ (entry 6) or phenylalanine methyl ester 8a (entry 7) could be obtained in excellent conversions. It must be mentioned that in this last example, the reaction was stopped after $8 \mathrm{~h}$ since longer times favoured the ester moiety hydrolysis.

Although showing a broad scope, some limitations were found for this methodology (Fig. 1). For instance, this system did not work for 
$N, N$-dibenzylated amine ( \pm )-9a, $O$-benzylated amino alcohol $( \pm)$ trans-10a, and $N$-protected piperidin-4-ol 11a. In the first case just minor quantities of the mono- and deprotected compounds were detected, and for the other two derivatives no conversion was attained. This is in line with previous reports based on Cu-nitroxyl oxidative systems, which show the oxidation of benzylic amines into the corresponding imines when they are mono- or di- (but not tri-)substituted. ${ }^{37,38}$

Limitations of this methodology

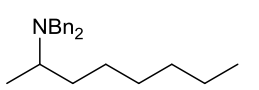

$( \pm)-9 a$

$( \pm)-2 a, 8 \%$

$( \pm)-2 b, 4 \%$

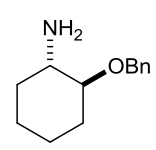

( \pm -trans-10a

(土)-trans-5b, $<1 \%$

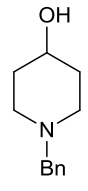

$11 \mathrm{a}$

11b, $<1 \%$
Fig. 1 Substrates showing low or depleted conversion using this method.

Based on these results, we decided to test the behaviour of diprotected substrates 12a and ( \pm )-trans-13a (Scheme 3). Primary amines were selectively deprotected irrespective of whether a secondary amine or an alcohol moiety appeared also benzylated in the molecule. These transformations are remarkable as there are just few selective examples described in the literature. ${ }^{8,9,39-41}$ These results open the door for the development of regio- and chemoselective processes that can hardly be performed by means of more conventional chemical methods.<smiles>BrCc1ccccc1</smiles>

12a

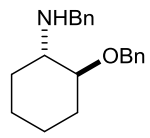

( \pm -trans-13a
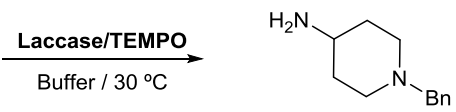

12b, $99 \%$
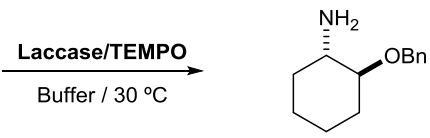

(土)-trans-10a, 99\%
Scheme 3 Chemoselective $\mathrm{N}$-debenzylation of primary amines vs secondary amines or alcohols using the laccase/TEMPO system.

Furthermore, some of these deprotections were done at $100-\mathrm{mg}$ scale and the amount of TEMPO could be reduced to $20 \% \mathrm{~mol}$ without any conversion decrease obtaining, after a simple extraction protocol, the corresponding amines in very high isolated yields ( $>80 \%$, see ESI for more information).

Encouraged by these promising results, we decided to compare the reactivity of our methodology with both laccase/AZADO and $\mathrm{CuCl} / \mathrm{AZADO}$ pairs, described as selective oxidative methods. ${ }^{34,35}$ For this study, $N$-benzylated amino alcohols 1a, $( \pm$ )-trans-5a and 11a were used as model substrates (Table 2). The laccasedependent system showed a similar behaviour, oxidizing the $\mathrm{N}$ position rather than the oxygen moiety (entries 1, 2, 4, 5, 7 and 8), although at lower extent. $\mathrm{CuCl} / \mathrm{AZADO}$ favoured the formation of the carbonylic compounds via alcohol oxidation (entries 3, 6 and 9). These complementary methods can overcome a challenge in synthetic organic chemistry such as the chemoselective oxidation of alcohols in the presence of amines functional groups and vice versa. $^{42,43}$ Remarkably, in the case of substrate 1a, the laccase/AZADO system, after $N$-benzyl deprotection and subsequent amine reoxidation led to a mixture of hemiacetal 1d and lactone 1e (Scheme 2) in a ratio 7.7:1. In contrast, for the $\mathrm{CuCl} / \mathrm{AZADO}$ pair, after alcohol oxidation into the corresponding aldehyde and intramolecular cyclization, the hemiaminal intermediate dehydrated giving access to enamine $\mathbf{1 f}(18 \%$ conv, see Scheme S3 in ESI).

Table 2 Reactivity of $N$-benzylated amino alcohols 1a, 5a and 11a using laccase/TEMPO, laccase/AZADO and $\mathrm{CuCl} / \mathrm{AZADO}$ systems ${ }^{a}$

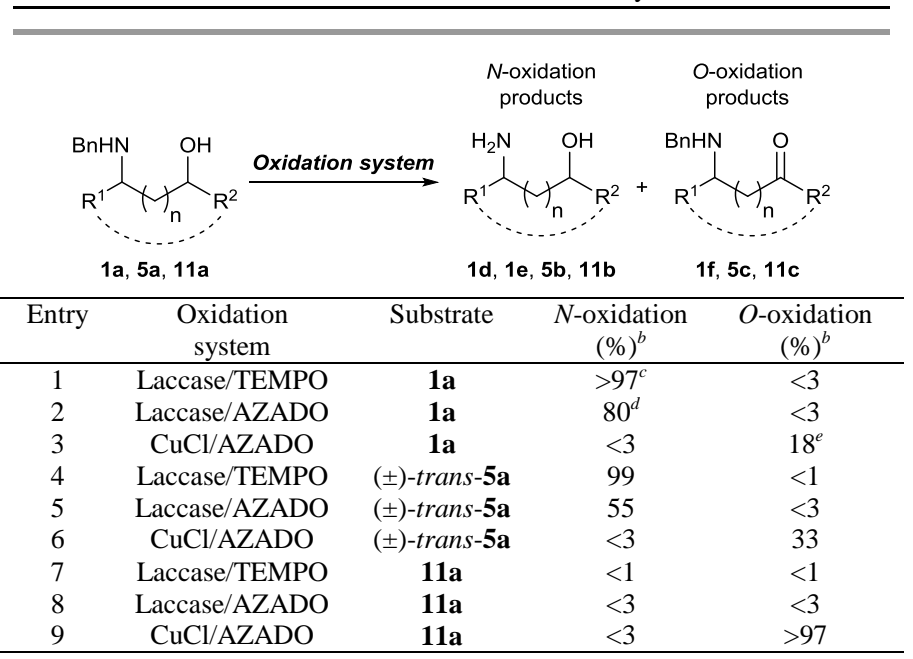

${ }^{a}$ For reaction conditions, see ESI. ${ }^{b}$ Conversion values measured by GC or NMR. ${ }^{c}$ Mixture of $\mathbf{1 d : 1 e}(1.5: 1) .{ }^{d}$ Mixture of 1d:1e $(7.7: 1) .{ }^{e}$ Formation of enamine 1f.

To demonstrate the excellent chemoselectivity of the laccase/TEMPO system for the deprotection of $\mathrm{N}$-benzylated amines, different chemical methods were assessed applied to $\mathrm{N}, \mathrm{O}$ dibenzylated compound ( \pm )-trans-13a. Among the previous methodologies that were described as mild and selective to achieve similar reactions, we chose $\mathrm{Pd} / \mathrm{C}$ in the presence of $\mathrm{H}_{2}$ or 1,4cyclohexadiene, ${ }^{39} \mathrm{CAN}^{8,40}$ and DIAD. ${ }^{9}$ The application of $\mathrm{Pd} / \mathrm{C}$ and 1,4-cyclohexadiene did not lead to any measurable conversion and CAN preferentially deprotected the ether moiety affording ( \pm )trans-5a. Only the employment of hydrogen with $\mathrm{Pd} / \mathrm{C}$ and DIAD allowed the synthesis of the desired derivative $( \pm)$-trans-10a in $27 \%$ and $80 \%$ yield, respectively, after column chromatography isolation.

To show the environmental benefits of this laccase-mediated system, ${ }^{44}$ a simplified environmental impact analysis making use of the $E$-factor ${ }^{45}$ concept was performed. Hence, the laccase/TEMPO system was compared with the other two $\left(\mathrm{H}_{2}-\mathrm{Pd} / \mathrm{C}\right.$ and DIAD) which afforded the final product 10a, making use of EATOS tool. ${ }^{46,47}$ An E-factor of 21.5 was obtained for our process (excluding solvents), while values higher than 380 for the others (see ESI for 
details). Also the solvent demand in our methodology $(560 \mathrm{~mL} / \mathrm{g}$ product) was much lower in comparison with the other strategies. These data demonstrate the favorable ecological impact of the laccase/TEMPO pair not only due to the natural source of one of the catalysts employed, but also because the simple isolation protocol needed and the excellent yield attained.

\section{Conclusions}

It is noteworthy the rise of contributions related to the application of laccases with synthetic purposes during the last few years. These oxidases can achieve mild oxidations in aqueous media and are compatible with different chemical oxidants, which has broadened their applicability in many (environmentally-friendly) processes. ${ }^{23-}$ 27 While finding important roles in numerous oxidative transformations, only Rutjes and co-workers have performed a systematic study of these systems applied to the deprotection of amines when PMP group was employed. ${ }^{22}$ Herein we have shown that this system can perfectly work for the removal of the benzyl moiety, widely utilized to protect amines and alcohols. While conventional deprotection methods make use of metal catalysts under hydrogenolysis conditions, Lewis acids or oxidative protocols employing organic solvents as reaction media, the methodology presented in this contribution operates in aqueous media under mild conditions using oxygen as final electron acceptor. Moreover, due to the cleanness of this protocol, final derivatives can be attained in high purity after a simple extraction, also leading to a lower environmental impact. While this reaction occurs efficiently for $N$-benzylated primary amines, it did not modify $O$-benzylated alcohols or $N$-protected secondary amines, allowing interesting regio- and chemoselective transformations, which cannot be easily accomplished by other chemical means. Overall, we present here a simple, mild and environmentallyfriendly synthetic protocol to remove the $N$-benzyl group, which can be ideally suited for widespread use in synthetic chemistry, e.g. amino acid or nucleoside chemistry.

\section{Acknowledgments}

Financial support from MICINN (Projects CTQ2011-24237 and CTQ2013-44153) is gratefully acknowledged. L.M.-M. thanks the Principado de Asturias for her predoctoral fellowship Severo Ochoa.

\section{Notes and references}

a Department of Organic and Inorganic Chemistry, Biotechnology Institute of Asturias, University of Oviedo, Avenida Julián Clavería 8, 33006 Oviedo, Spain.

b Actual address: Medicines Research Centre, GlaxoSmithKline R\&D Ltd, Gunnels Wood Road, Stevenage, Hertfordshire, SG1 2NY, UK.

Electronic Supplementary Information (ESI) available: [experimental procedures, substrate characterization, E-factor calculations, analytical data, and NMR spectra are described]. See DOI: $10.1039 / \mathrm{c} 000000 \mathrm{x} /$
1 T. W. Green and P. G. M. Wuts, Greene's Protective Groups in Organic Synthesis, 4th ed.; John Wiley \& Sons: New York, 2007.

2 Chiral Amine Synthesis: Methods, Developments and Applications, T. C. Nugent, Ed., Wiley-VCH: Weinheim, 2010.

3 M. Čerňová, I. Čerňa, R. Pohl and M. Hocek, J. Org. Chem., 2011, 76, 5309-5319.

4 S. G. Davies, A. M. Fletcher, D. G. Hughes, J. A. Lee, P. D. Price, P. M. Roberts, A. J. Russell, A. D. Smith, J. E. Thomson and O. M. H. Williams, Tetrahedron, 2011, 67, 9975-9992.

5 T. Farooq, L. K. Sydnes, K. W. Törnroos and B. E. Haug, Synthesis, 2012, 44, 2070-2078.

6 H. Ji, Q. Jing, J. Huang and R. B. Silverman, Tetrahedron, 2012, 68, 1359-1366.

7 M. Seki, Synthesis, 2014, 46, 3249-3255.

8 S. D. Bull, S. G. Davies, G. Fenton, A. W. Mulvaney, R. S. Prasad and A. D. Smith, J. Chem. Soc, Perkin Trans 1, 2000, 3765-3774.

9 J. Kroutil, T. Trnka, and M. Černý, Synthesis, 2004, 446-450.

10 S. Talukdar, S. K. Nayak and A. Banerji, J. Org. Chem., 1998, 63, 49254928.

11 K. Moriyama, Y. Nakamura and H. Togo, Org. Lett., 2014, 16, 38123815.

12 E. Paliakov and L. Strekowski, Tetrahedron Lett., 2004, 45, 40934095.

13 C. M. Clouthier and J. N. Pelletier, Chem. Soc. Rev., 2012, 41, 15851605.

14 M. Schmidt, E. Barbayianni, I. Fotakopoulou, M. Höhne, V. Constantinou-Kokotou, U. T. Bornscheuer and G. Kokotos, J. Org. Chem., 2005, 70, 3737-3740.

15 E. Barbayianni, I. Fotakopoulou, M. Schmidt, V. ConstantinouKokotou, U. T. Bornscheuer and G. Kokotos, J. Org. Chem., 2005, 70, 8730-8733.

16 I. Fotakopoulou, E. Barbayianni, V. Constantinou-Kokotou, U. T. Bornscheuer and G. Kokotos, J. Org. Chem., 2007, 72, 782-786.

17 E. Barbayianni, C. G. Kokotos, S. Bartsch, C. Drakou, U. T. Bornscheuer and G. Kokotos, Adv. Synth. Catal., 2009, 351, 2325-2332.

18 K. Thodi, E. Barbayianni, I. Fotakopoulou, U. T. Bornscheuer, V. Constantinou-Kokotou, P. Moutevelis-Minakakis and G. Kokotos, J. Mol. Catal. B: Enzym., 2009, 61, 241-246.

19 C. Simons, J. G. E. van Leeuwen, R. Stemmer, I. W. C. E. Arends, T. Maschmeyer, R. A. Sheldon and U. Hanefeld, J. Mol. Catal. B: Enzym., 2008, 54, 67-71.

20 L. N. Chu, V. B. Nanduri, R. N. Patel and A. Goswami, J. Mol. Catal. B: Enzym., 2013, 85-86, 56-60.

21 S. S. Kim, G. Lin and J. W. Yang, Bull. Korean Chem. Soc., 2004, 25, 249-252.

22 J. M. M. Verkade, L. J. C. van Hemert, P. J. L. M. Quaedflieg, H. E. Schoemaker, M. Schürmann, F. L. van Delft and F. P. J. T. Rutjes, Adv. Synth. Catal., 2007, 349, 1332-1336.

23 S. Riva, Trends Biotechnol., 2006, 24, 219-226.

24 S. R. Couto and J. L. T. Herrera, Biotech. Adv., 2006, 24, 500-513.

25 S. Witayakran and A. J. Ragauskas, Adv. Synth. Catal., 2009, 351, 1187-1209.

26 T. Kudanga, G. S. Nyanhongo, G. M. Guebitz and S. Burton, Enzyme Microb. Technol., 2011, 48, 195-208.

27 M. Mogharabi and M. A. Faramarzi, Adv. Synth. Catal., 2014, 356, 897-927. 
28 M. Fabbrini, C. Galli, P. Gentili and D. Macchitella, Tetrahedron Lett., 2001, 42, 7551-7553.

29 I. W. C. E. Arends, Y.-X. Li, R. Ausan and R. A. Sheldon, Tetrahedron, 2006, 62, 6659-6665.

30 A. Díaz-Rodríguez, I. Lavandera, S. Kanbak-Aksu, R. A. Sheldon, V. Gotor and V. Gotor-Fernández, Adv. Synth. Catal., 2012, 354, 34053408.

31 K. Kędziora, A. Díaz-Rodríguez, I. Lavandera, V. Gotor-Fernández and V. Gotor, Green Chem., 2014, 16, 2448-2453.

32 J. Gross, K. Tauber, M. Fuchs, N. G. Schmidt, A. Rajagopalan, K. Faber, W. M. F. Fabian, J. Pfeffer, T. Haas and W. Kroutil, Green Chem., 2014, 16, 2117-2121.

33 N. E. Leadbeater and J. M. Bobbitt, Aldrichim. Acta, 2014, 47, 65-74.

34 C. Zhu, Z. Zhang, W. Ding, J. Xie, Y. Chen, J. Wu, X. Chen and H. Ying, Green Chem., 2014, 16, 1131-1138.

35 Y. Sasano, S. Nagasawa, M. Yamazaki, M. Shibuya, J. Park and Y. Iwabuchi, Angew. Chem. Int. Ed., 2014, 53, 3236-3240.

36 A. Díaz-Rodríguez, L. Martínez-Montero, I. Lavandera, V. Gotor and V. Gotor-Fernández, Adv. Synth. Catal., 2014, 356, 2321-2329.

37 T. Sonobe, K. Oisaki and M. Kanai, Chem. Sci., 2012, 3, 3249-3255.

38 Z. Hu and F. M. Kerton, Org. Biomol. Chem., 2012, 10, 1618-1624.

39 J. S. Bajwa, J. Slade and 0. Repič, Tetrahedron Lett., 2000, 41, 60256028.

40 B. Hungerhoff, S. S. Samanta, J. Roels and P. Metz, Synlett, 2000, 7779.

41 E. J. Grayson and B. G. Davis, Org. Lett., 2005, 7, 2361-2364.

42 S. Desjardins, G. Jacquemot and S. Canesi, Synlett, 2012, 23, 14971500.

43 J. Srogl and S. Voltrova, Org. Lett., 2009, 11, 843-845.

44 Y. Ni, D. Holtmann and F. Hollmann, ChemCatChem, 2014, 6, 930943.

45 R. A. Sheldon, Chem. Ind., 1992, 903-906.

46 M. Eissen and J. O. Metzger, Chem.-Eur. J., 2002, 8, 3580-3585.

47 EATOS: Environmental Assessment Tool for Organic Syntheses, http://www.metzger.chemie.uni-oldenburg.de/eatos/english.htm, Accessed: 05.02.2014. 